\title{
PENGARUH PENERAPAN CHRONIC CONDITION SELF-MANAGEMENT (CCSM) TERHADAP KEPATUHAN PENGOBATAN PASIEN HIPERTENSI PESERTA PROLANIS BPJS DI MALANG JAWA TIMUR
}

\author{
Effect of Implementing The Self-Cronic Condition of Self Management (CCSM) on The Compliance of Treatment of \\ Hypertension Patients in Prolanis BPJS Participants in Malang East Java \\ 1*Lilis Sulistiya Nengrum, ${ }^{2}$ Angga Setya Wahyudi \\ ${ }^{1}$ STIKes Widya Cipta Husada, Malang, Jawa Timur \\ ${ }^{2}$ STIKes Widya Cipta Husada, Malang, Jawa Timur \\ *e-mail : lilissulistiya01@gmail.com
}

\begin{abstract}
ABSTRAK
Hipertensi sering disebut sebagai pembunuh diam-diam karena pada umumnya penderita tidak menyadari bahwa dirinya mengalami hipertensi. Keberhasilan suatu pengobatan tidak hanya dipengaruhi oleh kualitas pelayanan kesehatan, sikap/keterampilan petugasnya, pola hidup pasien beserta keluarganya, tetapi juga dipengaruhi oleh kepatuhan pasien terhadap pengobatannya. Chronic Condition Self-Managemen (CCSM) adalah sebuah pedoman yang dikembangkan untuk membantu perawat dan profesional kesehatan memfasilitasi pengelolaan diri pada klien kondisi penyakit kronis dengan menyediakan kerangka kerja untuk interaksi yang efektif dan strategi manajemen. Penelitian ini bertujuan untuk mengetahui pengaruh penerapan CCSM terhadap kepatuhan pengobatan. Penelitian ini dilakukan di DPS dr. Suhartatik Gondang Legi pada bulan Febuari - Juli 2017. Desain penelitian yang digunakan adalah Quasi-Eksperimental, dengan pre test and post test with one group design. Jumlah populasi 35 orang dengan sampel 20 responden menjadi satu kelompok intervensi, dengan teknik purposive sampling. Variabel tidak terikat yaitu CCSM dan variable terikat yaitu kepatuhan pengobatan. Instrumen mengunakan lembar ceklist dan lembar kuisoner kepatuhan pengobatan. Berdasarkan uji statistik paired t-test didapatkan hasil $\mathrm{p}$ value $0.000(\mathrm{p}<0.05)$ maka dapat disimpulkan bahwa ada pengaruh yang signifikan dari penerapan CCSM terhadap kepatuhan pengobatan. Berdasarkan hasil penelitian ini, diharapkan perawat dapat menggunakan CCSM sebagai suatu program promosi kesehatan untuk meningkatkan kepatuhan pengobatan pada pasien Hipertensi kronis.
\end{abstract}

Kata kunci : CCSM, kepatuhanpengobatan, hipertensikronis.

\begin{abstract}
Hypertension is often called the silent killer because most people do not realize that he had hypertension. The success of treatment is not only influenced by the quality of health services, attitudes / skills of its officers, the pattern of life of patients and their families, but also influenced bypatient adherence to treatment. Chronic Condition Self-Management (CCSM) is a guideline that wasdeveloped to help nurses and health professionals on the client facilitates self-management of chronicconditions by providing a framework for effective interaction and management strategies. This studyaims to determine theeffect of the application of CCSM on treatment compliance. This research wasconducted in the DPS dr. SuhartatikGondangLegi in February - July 2017. The study design usedwas Quasi-Experimental,with pre-test and post-test with one group design. Total population 35 with asample of 20 respondents into an intervention group, with atechnique purposive sampling. The dependent variable is CCSM and independen variable and treatment compliance. Instruments using achecklist sheet and medication adherence questionnaire sheet. Based on statistical test paired t-test showed the $p$ value 0.000 ( $p<0.05)$, it can be concluded that there is a significant effect of the application of CCSM on treatment compliance. Based on these results, it is expected the nurse can useCCSM as a health promotion program to improve medication adherence in patients with chronichypertension.
\end{abstract}

Key words: CCSM, treatment adherence, chronic hypertension

\section{PENDAHULUAN}

Hipertensi didefinisikan sebagai peningkatan tekanan darah sistolik sedikitnya $140 \mathrm{mmHg}$ atau tekanan darah diastolik sedikitnya $90 \mathrm{mmHg}{ }^{[10]}$.
Jumlah penderita hipertensi akan terus meningkat seiring dengan jumlah penduduk yang semakin bertambah banyak, pada tahun 2025 mendatang diperkirakan sekitar 29\% warga dunia menderita 
BJMLT

hipertensi. Persentase penderita hipertensi saat ini paling banyak terdapat di negara berkembang yaitu $40 \%$ penderita, sedangkan di negara maju penderita hipertensi hanya $35 \%{ }^{[13]}$.

Berdasarkan penelitian dilaporkan bahwa hanya sebagian kecil $(22,8 \%)$ penderita hipertensi di Indonesia yang periksa secara teratur di Puskesmas, sedangkan sisanya hampir seluruhnya $(77,2 \%)$ tidak teratur. Dari pasien hipertensi dengan riwayat periksa tidak teratur, $91,7 \%$ tekanan darahnya belum terkontrol. Sedangkan kelompok pasien yang mengaku periksa teratur dalam tiga bulan terakhir dilaporkan seluruhnya (100\%) masih mengidap hipertensi ${ }^{[1]}$. Banyak pasien hipertensi dengan tekanan darah tidak terkontrol dan jumlahnya terus meningkat. Partisipasi semua pihak, baik dokter dari berbagai bidang peminatan hipertensi, pemerintah, swasta maupun masyarakat diperlukan agar hipertensi dapat dikendalikan ${ }^{[3]}$.

Keberhasilan suatu pengobatan tidak hanya dipengaruhi oleh kualitas pelayanan kesehatan, sikap dan keterampilan petugasnya, sikap dan pola hidup pasien beserta keluarganya, tetapi juga dipengaruhi oleh kepatuhan pasien terhadap pengobatannya. Hasil terapi tidak akan mencapai tingkat optimal tanpa adanya kesadaran dari pasien itu sendiri, bahkan dapat menyebabkan kegagalan terapi serta dapat menimbulkan komplikasi yang sangat merugikan dan pada akhirnya dapat berakibat fatal ${ }^{[5]}$.

Komplikasi hipertensi diantaranya adalah infark miokard, gagal ginjal ensefalopati (kerusakan otak), dan stroke ${ }^{[2]}$. Komplikasi hipertensi setidaknya sudah menyebabkan $45 \%$ kematian karena penyakit jantung dan $51 \%$ kematian karena penyakit stroke. Kematian yang disebabkan oleh penyakit kardiovaskuler, terutama penyakit jantung koroner dan stroke diperkirakan akan terus meningkat mencapai 23,3 juta kematian pada tahun 2030 [3] Karena pentingnya mengelola penyakit hipertensi kronik untuk meminimalkan komplikasi, salah satu cara dalam mengelola hipertensi kronis adalah dengan Chronic Condition Self-Managemen (CCSM).

CCSM adalah sebuah pedoman yang dikembangkan untuk membantu perawat dan profesional kesehatan memfasilitasi pengelolaan diri pada klien kondisi penyakit kronis dengan menyediakan kerangka kerja untuk interaksi yang efektif dan strategi manajemen. Manfaat dari CCSM sendiri sangat bagus dimana pasien diberi beberapa intervensi untuk memberi suport pasien yang dalam kondisi kronis, seperti memberi edukasi dan informasi tentang penyakitnya, wawancara motivasi kepada pasien, dan membuat suatu catatan monitoring penyakit untuk memantau penyakit kronis [12]. Tujuan dari penelitian ini adalah untuk mengetahui pengaruh penerapan CCSM terhadap kepatuhan pengobatan pasien hipertensi peserta Prolanis BPJS di DPS dr. Suhartatik Gondang Legi.

\section{METODE PENELITIAN}

\section{Desain Penelitian}

Penelitian ini merupakan penelitian experimental. Metode penelitian yang digunakan adalah quasy experiment design (rancangan eksperimen semu) dengan desain penelitian one group pretest posttest ${ }^{[7]}$. Rancangan penelitian ini bertujuan untuk mengetahui pengaruh penerapan CCSM terhadap kepatuhan pengobatan peserta hipertensi. Responden dalan penelitian hanya terbagi menjadi 1 kelompok intervensi (perlakukan), dimana satu kelompok intervensi ini dilakukan observasi terlebih dahulu (pre-test) sebelum dilakukan intervensi, kemudian diobservasi lagi setelah dilakukan intervensi (post-test).।

\section{HASIL DAN PEMBAHASAN}

Tabel 1 : Distribusi Frekuensi Kunjungan Pasien Hipertensi Peserta Prolanis BPJS Sesudah Pelaksanaan CCSM pada Tanggal 2 Mei 2017 - 16 Mei 2017.

\begin{tabular}{ccc}
\hline No & Kategori & $\begin{array}{c}\text { Jumlah } \\
\text { (Persen) }\end{array}$ \\
\hline 1 & Hadir & $13(65 \%)$ \\
\hline 2 & Tidak Hadir & $7(35 \%)$ \\
\hline & Jumlah & $20(100 \%)$ \\
\hline Sumber $:$ Data primer bulan Mei 2017
\end{tabular}

Berdasarkan tabel 1 dapat diketahui bahwa sebagian besar responden hadir sebanyak 13 orang $(65 \%)$, dan hampir separuh tidak hadir yaitu 7 orang (35\%), dari validasi data post-test ke-2 kepatuhan kunjungan pasien sebagain besar hadir sebanyak 12 orang $(60 \%)$. Data pada tabel 1 berbanding tertabik dengan penelitian Mochammad Sja'bani [1] 
BJMLT

dilaporkan bahwa hanya sebagian kecil (22,8 \%) penderita hipertensi di Indonesia yang periksa secara teratur di Puskesmas, sedangkan sisanya hampir seluruhnya $(77,2 \%)$ tidak teratur. Berarti dapat disimpulkan bahwa setelah penerapan CCSM mempunyai pengaruh yang signifikan terhadap kepatuhan kunjungan pasien hipertensi.

Tabel 2 : Kepatuhan pengobatan pasien hipertensi peserta Prolanis BPJS sebelum pelaksanaan CCSM (pretest).

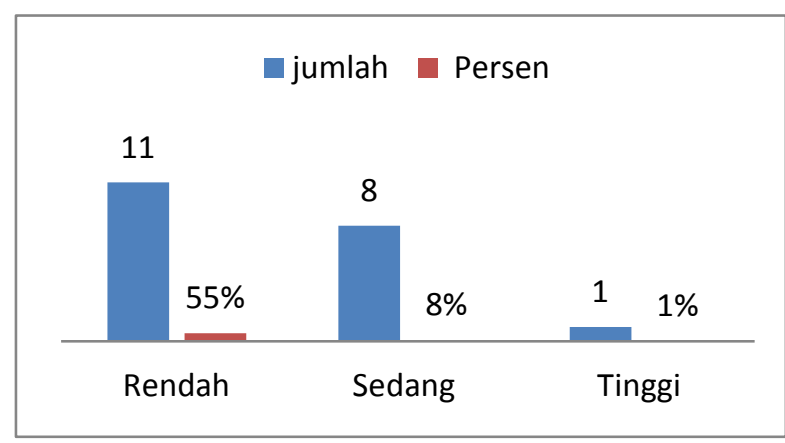

Sumber : Data primer bulan Mei 2017

Berdasarkan hasil penelitian pada tabel 2 dapat diketahui bahwa sebagian besar kategori kepatuhan rendah sebanyak 11 orang (55\%), dan sebagian kecil berkategori kepatuhan tinggi hanya 1 orang $(5 \%)$. Sedangkan dari data umum status pekerjaan responden diketahui hampir separuhnya sebagai pekerja pabrik sebanyak 9 orang (45\%), sebagaian kecil karyawan POM 3 orang (15\%), sebagaian kecil karyawan PLN 3 orang (15\%), karyawan toko 2 orang (10\%), IRT 2 orang (10\%) dan guru SD 1 orang $(5 \%)$.

'Faktor-faktor yang berhubungan dengan kepatuhan pengobatan pada penderita hipertensi di wilayah kerja Puskesmas Kedungmundu Kota Semarang'. ${ }^{[9]}$ Hasil penelitian menunjukkan bahwa faktor-faktor yang berhubungan dengan kepatuhan pengobatan hipertensi adalah status pekerjaan ( $p$ value $=0.035)$, jarak rumah terhadap pelayanan kesehatan ( $p$ value $=0.014)$, tingkat pengetahuan tentang tatalaksana hipertensi ( $p$ value $=0.000)$, motivasi untuk berobat ( $p$ value $=0.000)$, dan dukungan keluarga ( $p$ value $=0.000$ ).

Melihat dari uraian diatas dapat disimpulkan status pekerjaan responden diperkirakan dapat mempengauhi kepatuhan pengobatan peserta hipertensi Prolanis BPJS. Berdasarakan tabel 3 diketahui bahwa hampir separuh yaitu sebanyak 9 orang $(45 \%)$ responden memiliki status pekerjaan sebagai karyawan pabrik. Diketahui bahwa pekerja pabrik mempunyai sift jam kerja yang tidak memungkinkan untuk mengelola life style dan untuk kontrol ke fasilitas kesehatan. Ditambah dengan keterbatasan petugas kesehatan untuk memonitoring pasien hipertensi karena hanya terdapat 1 orang tenaga kesehatan di DPS dr. Suhartatik Gondang Legi.

Tabel 3 : Kepatuhan pengobatan pasien hipertensi peserta Prolanis BPJS sesudah pelaksanaan CCSM (pretest).

\begin{tabular}{ccc}
\hline No & Kategori & $\begin{array}{c}\text { Jumlah } \\
\text { (Persen) }\end{array}$ \\
\hline 1 & Rendah & $0(0 \%)$ \\
\hline 2 & Sedang & $9(45 \%)$ \\
\hline 3 & Tinggi & $11(55 \%)$ \\
\hline Sumber : Data primer bulan Mei 2017
\end{tabular}

Berdasarkan hasil penelitian pada tabel 4 dapat diketahui bahwa sebagian besar kategori kepatuhan tinggi sebanyak 11 orang (55\%), hampir separuhnya kategori kepatuhan sedang sebanyak 9 orang (45\%), berdasarkan validasi data pada post-test ke-2 menunjukkan frekuensi kepatuhan pengobatan masih tetap yaitu sebagian besar kategori kepatuhan tinggi sebanyak 11 orang $(55 \%)$.

Ada beberapa faktor yang signifikan mempengaruhi kepatuhan dalam pengobatan hipertensi antara lain; tingkat pengetahuan $(\mathrm{p}=0.015)$, motivasi ( $\mathrm{p}=0.02)$, dukungan petugas $(\mathrm{p}=0.048)$, dukungan keluarga $(\mathrm{p}=0.000)$ dan jumlah jenis obat yang dikonsumsi $(\mathrm{p}=0.485)$. Faktor yang mempengaruhi kepatuhan menurut antara lain: motiasi klien untuk sembuh, tingkat perubahan gaya hidup, warisan budaya, biaya terapi, tingkat kepuasan dan konumikasi keluarga efektif. Faktor yang mepengaruhi kepatuhan diantaranya : kepercayaan atau agama yang dianut, faktor geografis lingkungan, keinginan sembuh, pengetahuan penderita, dukungan petugas, dukungan keluarga, dan fasilitas kesehatan seperti memberi penyuluhan terhadap penderita.

Berdasarkan penjelasan diatas dapat disimpulakan bahwa pengaruh pengetahuan, motivasi dan kartu monitoring dapat mempengaruhi kepatuhan. Data diperkuat dari penelitian , menyatakan bahwa semakin baik pengetahuan dan 
BJMLT

dukungan keluarga yang dimiliki penderita DM maka akan meningkatkan kepatuhan penderita DM dalam melakukan penatalaksanaan DM. Pada Chronic Condition Self-Management(CCSM) terdapat beberapa intervensi yang dapat mendukung pasien dalam kondisi kronis, seperti memberi edukasi dan informasi tentang penyakitnya, wawancara motivasi kepada pasien, dan membuat suatu catatan monitoring penyakit untuk memantau penyakit kronis.

Perubahan perilaku bisa saja terjadi setelah penerapan CCSM karena menurut teori perubahan perilaku kesehatan, pertimbangan ini meliputi:evaluasi mengenai risiko / kerentanan terhadap ancaman kesehatan, persepsi keseriusan penyakit, kegunaan dari tindakan yang diambil untuk menghindari komplikasi atau penyakit dan hambatan yang dapat mencegah penatalaksanaan yang dianjurkan. Berarti dapat disimpulkan bahwa setelah penerapan CCSM mempunyai pengaruh yang signifikan terhadap kepatuhan pengobatan pasien hipertensi peserta Prolanis BPJS.

Tabel 4 : Analisis pengaruh penerapan Chronic Condition SelfManagement(CCSM) terhadap kepatuhan pengobatan pasien hipertensi peserta Prolanis BPJS.

\begin{tabular}{|l|l|l|l|l|l|l|l|l|}
\hline \multirow{2}{*}{$\begin{array}{l}\text { Rost } \\
\text { Pre }\end{array}$} & \multicolumn{2}{|l|}{ Rendah } & \multicolumn{2}{l|}{ Sedang } & \multicolumn{2}{l|}{ Tinggi } & \multicolumn{2}{|c|}{ Total } \\
\cline { 2 - 10 } & $\mathrm{F}$ & $\%$ & $\mathrm{~F}$ & $\%$ & $\mathrm{f}$ & $\%$ & $\mathrm{~F}$ & $\%$ \\
\hline Rendah & 0 & 0 & 9 & 45 & 2 & 10 & 11 & 55 \\
\hline Sedang & 0 & 0 & 0 & 0 & 8 & 40 & 8 & 40 \\
\hline Tinggi & 0 & 0 & 0 & 0 & 1 & 5 & 1 & 5 \\
\hline Total & 0 & 0 & 9 & 45 & 11 & 55 & 20 & 100 \\
\hline Hasil uji paired t-test, p value : $0.00(\mathrm{p}<0.05)$ \\
\hline
\end{tabular}

Sumber : Data primer bulan Mei 2017

Berdasarkan hasil penelitian pada tabel 4 dapat diketahui bahwa distribusi tabel silang pre-test dan post-test hampir separuh perubahan dari kepatuhan rendah ke kepatuhan sedang sebanyak 9 orang (45\%) dan sebagaian kecil tidak ada perubahan yaitu 1 orang (5\%) dari tinggi ke tinggi. Berdasarkan hasil uji statistik paired t-test didapatkan hasil $p$ value $0.000(\mathrm{p}<0.05)$ maka dapat disimpulkan bahwa ada pengaruh yang signifikan dari penerapan CCSM terhadap kepatuhan pengobatan.
Menurut penelitiansebelumnya, Chronic condition management and self-management di komunitas Aborigin di Australia Selatan. Data klinis berulang peserta dengan diabetes kondisi kronis (tipe 1 dan 2). Chronic condition management and selfmanagement program telah tersedia untuk orangorang Aborigin di berbagai bentuk untuk beberapa waktu. Hasil dari keterlibatan ini mengarah kepada peningkatan kualitas hidup dan kesehatan hasil bagi orang-orang Aborigin. Data ini memberikan bukti awal perbaikan berkelanjutan dari waktu ke waktu untuk kohort orang Aborigin yang sedang belajar untuk menghadapi berbagai penyakit kronis melalui akses sistem terstruktur dari dukungan perawatan.

Bedasarakan penelitian diatas dapat disimpulkan bahwa dari hasil penelitian ini dibandingkan dengan penelitian sebelumnya menunjukan data yang positif dengan penerapan Chronic Condition Self-Management (CCSM)terhadap pasien dalam kondisi kronis dengan hasil yang lebih baik. Berdasarkan uji statistik paired t-test didapatkan hasil $p$ value $0.000(\mathrm{p}<0.05)$ maka dapat disimpulkan bahwa ada pengaruh yang signifikan dari penerapan CCSM terhadap kepatuhan pengobatan.

Perubahan perilaku bisa saja terjadi setelah penerapan CCSM, karena dalam CCSM memiliki beberapa intervensi antara lain ; edukasi dan informasi mengenai penyakitnya, wawancara motivasi dan kartu monitoring penyakit. Sehingga setelah penerapan CCSM perubahan perilaku pasien hipertensi terhadapat kepatuhan pengobatan hipertensi mulai nampak, dijelasakan menurut teori perubahan perilaku kesehatan, pertimbangan ini meliputi:evaluasi mengenai risiko / kerentanan terhadap ancaman kesehatan, persepsi keseriusan penyakit, kegunaan dari tindakan yang diambil untuk menghindari komplikasi atau penyakit dan hambatan yang dapat mencegah penatalaksanaan yang dianjurkan.

\section{KESIMPULAN}

Berdasarkan hasil penelitian dapat disimpulkan, ada pengaruh penerapan CCSM terhadap kepatuhan pengobatan pasien hipertensi. Dengan rincian, kepatuhan kunjungan pasien hipertensi setelah penerapanCCSM mengalami 
BJMLT

peningkatan yang bermakna. Dan kepatuhan pengobatan pasien hipertensi setelah penerapanCCSM hampir separuh perubahan dari kepatuhan rendah ke kepatuhan sedang sebanyak 9 orang (45\%). Maka dapat disimpulkan bahwa ada pengaruh yang signifikan dari penerapan CCSM terhadap kepatuhan pengobatan pasien hipertensi peserta Prolanis BPJS di DPS dr. Suhartatik Gondang Legi.

Disarankandengan adanya penelitian ini diharapkan dapat menjadi masukan bagi pelayanan kesehatan dapat menggunakan CCSM sebagai suatu progam promosi kesehatan untuk meningkatkan kepatuhan pengobatan pada pasien hipertensi kronis dan meminimalkan komplikasi. Dan dapat digunakan sebagai intervensi alternatif dalam manajemen penyakit kronis hipertensi dengan menggunakan manajemen yang lebih berpengaruh dan efektif.Diharapkan bagi peneliti selanjutnya dapat mengembangkan penelitian ini dengan mengkaji faktor yang mempengaruhi kepatuhan dan melakukan observasi ataupun wawancara terhadap keluarga untuk validasi data tentang kepatuhan.

\section{DAFTAR PUSTAKA}

Alfiana, Nunik. 2014. Hubungan Asupan Kalsium dan Natrium Terhadap tekanan darah sistolik pada penderita hipertensi rawat inap di RS Tugurejo Semarang. (Online),(http//www.jurnal.unimus.ac.id diakses 18 Maret 2017).

Elizabeth J, Corwin. 2009. Patofisiologi : buku saku / Elizabeth J. Corwin ; alih bahasa, Nike Budhi Subekti ; editor edisi bahasa Indonesia, Egi Komara Yudha-Ed. 3 - Jakarta : EGC.

Kemenkes RI. 2014. Kementrian Kesehatan Republik Indonesia.

(Online),(www.depkes.go.id/download.php?fil e diakses 17 Maret 2017).

Kozier. 2010. Buku Ajar Praktik Keperawatan Klinis. Edisi 5, Jakarta : EGC.

Muljabar, S. M., \& Supadmi, W. 2014. Pengaruh Pemberian Informasi Obat Terhadap Tingkat Kepatuhan Penggunaan Antibiotika Pada Pasien ISPA di Puskesmas Kotagede I Yogyakarta. Jurnal Pharmaciana.
Notoatmodjo, S. 2012. Metodologi Penelitian Kesehatan Edisi Revisi Cetakan ke 2, Jakarta : Rineka Cipta.

Patrama, G.W., Ariastuti, N.L.P. 2014. Faktor-Faktor Yang Mempengaruhi Kepatuhan Hipertensi Pada Lansiabinaan Puskesmas Klungkun. Jurnal garuda

Rasajati, 2015. Faktor-faktor yang berhubungan dengan kepatuhan pengobatan pada penderita hipertensi di wilayah kerja Puskesmas Kedungmundu Kota Semarang. Jurnal UNNES

Sherwood, Lauralee. 2011. Fisiologi Manusia dari Sel ke Sistem Edisi Bahasa Indonesia, -Ed.6, Jakarta : EGC.

Siti Shofiyah, Henni Kusuma, 2014. Hubungan antara pengetahuan dan dukungan keluarga terhadap kepatuhan penderita diabetes melitus (DM) dalam penatalaksanaan di wilayah kerja Puskesmas Srondol Kecamatan Banyumanik Semarang. Jurnal Unimus

The Royal Australian College of General Practitionners, 2007. GuidelinesChronic Conditsion Self-Management, Australia.

World Health Organization. 2012."New data highlight increases in hypertension, diabetes incidence".(Online)

(www.who.int/mediacentre/news/releases/2012 diakses 17 Maret 2017). 